\title{
XÂY DỰNG MÔ HÌNH MẶT BIỂN TRUNG BÌNH VÀ MặT BIỂN THẤP NHẤT KHU VỰC TRÊN VÙNG BIỂN VIỆT NAM
}

\author{
KHƯƠNG VĂN LONG(1), LƯƠNG THANH THẠCH ${ }^{(2)}$, \\ TRẦN VĂN HẢI ${ }^{(3)}$, ĐẶNG XUÂN THỦY ${ }^{(4)}$ \\ (')Đoàn Đo đạc Biên vẽ hải đồ và Nghiên cưu biển \\ ${ }^{(2)}$ Truờng Đại học Tài nguyên và Môi trường Hà Nội \\ (3)Xí nghiệp Trắc địa, Công ty TNHH MTV Trắc địa Bản đồ \\ (4) Viện Khoa hoc Đo đạc và Bản đồ
}

\section{Tóm tắt}

Biển Đông được xác định là khu vực biển có tính chất thủy triều rất phức tạp, do vậy việc tính toán xác định các mặt chuẩn để xủ lý dũ liệu đo độ sâu gặp nhiều khó khăn. Hiện nay, độ cao mặt biển trung bình và mặt biển thấp nhất được tính toán dựa trên số liệu nghiệm triều với thời gian quan trắc tối thiểu 30 ngày và mỗi trạm cũng chỉ có hiệu lực trong phạm vi tù 30 đến $70 \mathrm{~km}$ tùy theo tính chất triều của tùng khu vực biển. Bài báo trình bày kết quả xây dụng mô hình mặt biển trung bình khu vục và mặt biển thấp nhất khu vưc trên vùng biển Việt Nam, làm cơ sở để quy chiếu các trị đo sâu địa hình đáy biển phục vu xây dựng nền thông tin địa lý biển và sản xuất hải đồ bảo đảm an toàn hàng hải.

\section{1. Đặt vấn đề}

Việt Nam có vùng biển rộng trên 1 triệu $\mathrm{km}^{2}$ và chiều dài bờ biển hơn $3.260 \mathrm{~km}$ với đủ các chế độ thuỷ triều trên thế giới như nhật triều đều, nhật triều không đều, bán nhật triều đều và bán nhật triều không đều; phân bố rất không đồng đều từ Móng Cái đến Hà Tiên và ngoài khơi Biển Đông. Hiện tượng thủy triều ở Biển Đông được thừa nhận là có tính chất rất phức tạp và thay đổi theo từng vùng biển [6]. Với chế độ thủy triều như vậy, kết hợp với điều kiện khắc nghiệt của khí tượng, sự biến thiên phức tạp của trường sóng mặt, sóng nội và các dòng chảy trên Biển Đông,... làm cho mặt biển luôn ở trạng thái động. Theo tài liệu [5], bề mặt tự nhiên biển là mặt biển trung bình có các "đồi - hills" và các "thung lũng - valeys" với độ cao chuẩn của các điểm nằm trên đó được xác định từ mặt geoid toàn cầu trên các biển và đại dương. Việc thành lập mô hình bề mặt tự nhiên biển MDT (Mean Dynamic Topography) dựa trên Hệ độ cao quốc gia được sử dụng làm nền thông tin địa lý và quy chiếu các kết quả đo sâu (sau khi cải chính thủy triều) về mặt geoid để xác định độ sâu phục vụ công tác thành lập bản đồ địa hình đáy biển.

Trong công tác tính toán mặt chuẩn độ sâu để thể hiện kết quả đo nối độ sâu địa hình đáy biển, đối với bản đồ địa hình đáy biển sử dụng mặt biển trung bình, còn với hải đồ sử dụng mặt biển thấp nhất. Việc tính toán, xác định số " 0 “ độ sâu cho các mặt chuẩn (mặt biển trung bình và mặt biển thấp nhất) đòi hỏi chuỗi số liệu quan trắc tương đối dài, tối thiểu từ 30 ngày $[1,2]$. Tuy nhiên theo kết quả nghiên cứu trong tài liệu [5] "mặt biển trung bình cục bộ được xác định theo các số liệu đo mực nước tại các trạm nghiệm triều dọc bờ biển Việt Nam không cho phép xác định bề mặt tự nhiên biển (mặt biển trung bình) trên toàn bộ Biển Đông“. Vì lý do đó, trong công trình [5] đã sử dụng mô hình địa hình động lực trung bình DTU10MDT để xây dựng mô hình mặt biển trung bình (MDTVN2015). Dựa trên độ cao chuẩn của các mặt biển cao nhất và thấp nhất tại 14 trạm nghiệm triều cố định và 22 trạm nghiệm triều tạm thời dọc bờ biển Việt Nam, công trình [5] đã xây dựng

Ngày nhận bài: 03/9/2018, ngày chuyển phản biện: 05/9/2018, ngày chấp nhận phản biện: 11/9/2018, ngày chấp nhận đăng: 18/9/2018 
được mô hình mặt biển cao nhất HSS2015 và mô hình mặt biển thấp nhất (LSS2015) trên vùng biển Việt Nam. Dựa trên độ cao chuẩn trong hệ triều 0 của 14 trạm nghiệm triều cố định dọc bờ biển và trên một số đảo của Việt Nam, công trình [5] đã đánh giá mô hình MDTVN2015 đạt độ chính xác $\pm 0,058 \mathrm{~m}$. Sử dụng độ cao chuẩn trong hệ triều 0 của 22 trạm nghiệm triều tạm thời dọc bờ biển để đánh giá, mô hình MDTVN2015 đạt độ chính xác $\pm 0,142 \mathrm{~m}$.

Theo nhận xét trong [5], các mô hình MDTVN2015, HSS2015 và LSS2015 sẽ phục vụ đắc lực cho nhiệm vụ xây dựng các công trình và quy hoạch đới bờ Việt Nam trong xu thế biến đổi khí hậu. Tuy nhiên, mô hình MDTVN2015 và mô hình LSS2015 vẫn chưa đáp ứng được một số yêu cầu đối với công tác thành lập cơ sở dữ liệu (CSDL) chuyên đề biển và hải đồ. Cụ thể như sau:

- Mô hình MDTVN2015 và mô hình LSS2015 không tính đến mặt chuẩn "0” độ sâu theo từng khu vực trong hệ triều trung bình.

- Mô hình mặt biển thấp nhất LSS2015 được xây dựng chỉ dựa trên độ cao mặt biển thấp nhất tại 36 trạm nghiệm triều dọc bờ biển Việt Nam và trên một số đảo, nên chưa đáp ứng được yêu cầu về độ chính xác để thành lập CSDL chuyên đề biển và hải đồ cho toàn bộ vùng biển Việt Nam.

Mặc dù vậy, phương pháp luận thành lập các mô hình MDTVN2015 và LSS2015 đã cho chúng tôi ý tưởng để xây dựng các mô hình mặt biển trung bình khu vực và mô hình mặt biển thấp nhất khu vực phục vụ sản xuất tư liệu biển trên vùng biển Việt Nam.

\section{Giải quyết vấn đề}

a. Số liệu phuc vu tính toán thực nghiệm

Các trạm nghiệm triều dọc bờ biển và trên một số đảo, quần đảo Việt Nam (xem hình 1) phục vụ xây dựng các mô hình mặt biển được lấy từ 2 nguồn:

- Báo cáo tổng hợp kết quả nghiên cứu khoa học và phát triển công nghệ đề tài cấp Nhà nước, Mã số KC.09.19/11-15 với sự cho phép của Chủ nhiệm đề tài PGS.TSKH Hà Minh Hòa, nguyên Viện trưởng Viện Khoa học Đo đạc và Bản đồ;

- Các trạm đo mực nước tạm thời của Đoàn Đo đạc Biên vẽ hải đồ và Nghiên cứu biển (Đoàn 6).

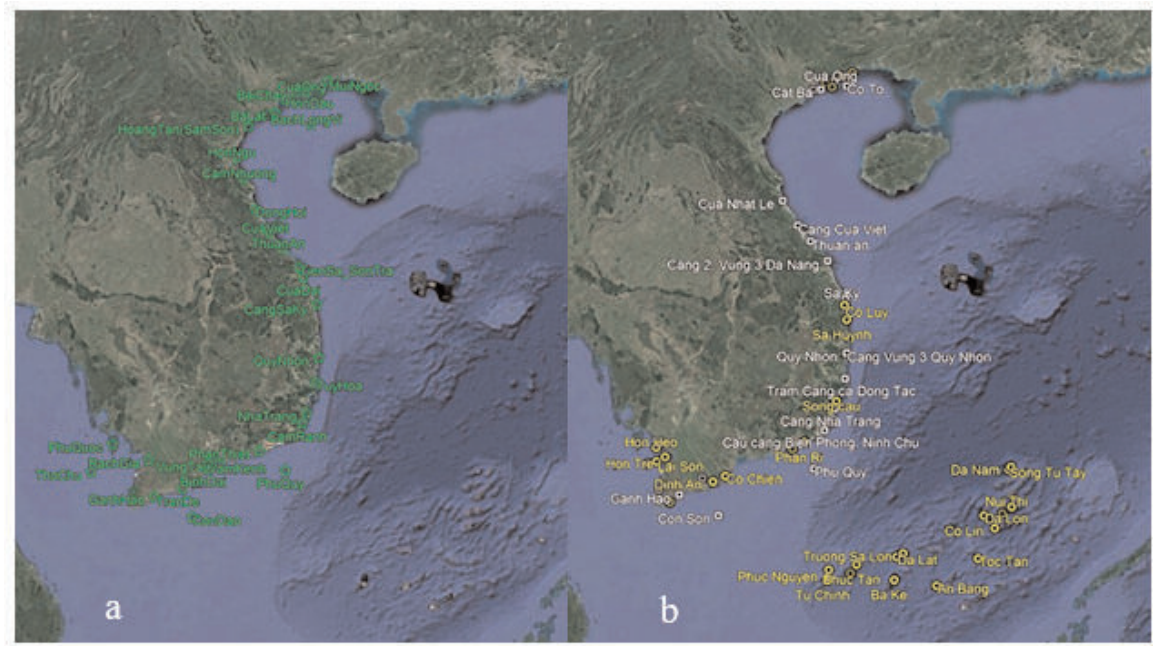

Hình 1: So đồ vị trí các trạm nghiệm triều trên vùng biển Việt Nam

a. Các trạm nghiệm triều thuộc công trình [5]; b. Các trạm nghiệm triều của Đoàn 6 [3] 
- Độ cao mặt biển trên các trạm nghiệm triều trong hệ triều 0 lấy từ [5], được tính chuyển về hệ triều trung bình và được thống kê trong bảng 1 .

Bảng 1: Độ cao mặt biển trên các trạm nghiệm triều (Nguồn [5])

\begin{tabular}{|c|c|c|c|c|}
\hline STT & Tên trạm & $\begin{array}{c}\text { Độ cao của các mặt biển } \\
\text { trung bình trong hệ độ cao } \\
\text { Hp72(m) }\end{array}$ & $\begin{array}{c}\text { Độ cao của các mặt biển } \\
\text { thấp nhất trong hệ độ cao } \\
\text { Hp72 (m) }\end{array}$ & $\begin{array}{l}\text { Độ chênh giữa mặt biển } \\
\text { trung bình và mặt biển } \\
\text { thấp nhất khu vực (m) }\end{array}$ \\
\hline (1) & (2) & (3) & (4) & (5) \\
\hline 1 & Cửa Ông & -0.005 & -2.145 & 2.140 \\
\hline 2 & Bãi Cháy & -0.069 & -2.409 & 2.340 \\
\hline 3 & Hòn Dấu & -0.062 & -2.132 & 2.070 \\
\hline 4 & Tiên Sa - Sơn Trà & 0.027 & -0.623 & 0.650 \\
\hline 5 & Quy Nhơn & -0.006 & -0.976 & 0.970 \\
\hline 6 & Nha Trang & -0.036 & -1.016 & 0.980 \\
\hline 7 & Vũng Tàu & -0.119 & -2.639 & 2.520 \\
\hline 8 & Cô Tô & 0.113 & -1.877 & 1.990 \\
\hline 9 & Bạch Long Vĩ & -0.060 & -1.890 & 1.830 \\
\hline 10 & Hòn Ngư & 0.017 & -1.703 & 1.720 \\
\hline 11 & Cồn Cỏ & -0.001 & -0.601 & 0.600 \\
\hline 12 & Phú Quý & 0.012 & -1.098 & 1.110 \\
\hline 13 & Côn Đảo & -0.048 & -2.328 & 2.280 \\
\hline 14 & Phú Quốc & -0.188 & -0.708 & 0.520 \\
\hline 15 & Thổ Chu & 0.023 & -0.257 & 0.280 \\
\hline 16 & Mũi Ngọc & 0.056 & -2.564 & 2.620 \\
\hline 17 & Ba Lạt & 0.125 & -2.065 & 2.190 \\
\hline 18 & Cửa Đáy (Nam Định) & 0.226 & -1.904 & 2.130 \\
\hline 19 & Hoàng Tân (Sầm Sơn) & -0.058 & -1.878 & 1.820 \\
\hline 20 & Cẩm Nhượng & 0.109 & -1.351 & 1.460 \\
\hline 21 & Đồng Hới & -0.073 & -1.213 & 1.140 \\
\hline 22 & Cửa Việt & -0.290 & -0.990 & 0.700 \\
\hline 23 & Thuận An & -0.218 & -0.668 & 0.450 \\
\hline 24 & Cửa Đại & -0.028 & -0.818 & 0.790 \\
\hline 25 & Cảng Sa Kỳ & 0.092 & -0.718 & 0.810 \\
\hline 26 & Tuy Hòa & -0.243 & -1.273 & 1.030 \\
\hline 27 & Cam Ranh & 0.076 & -0.994 & 1.070 \\
\hline 28 & Phan Rang & -0.028 & -1.168 & 1.140 \\
\hline 29 & Phan Thiết & 0.143 & -1.437 & 1.580 \\
\hline 30 & Vàm Kênh & 0.259 & -2.501 & 2.760 \\
\hline 31 & Bình Đại & 0.013 & -2.687 & 2.700 \\
\hline 32 & Trà Vinh & 0.093 & -2.777 & 2.870 \\
\hline 33 & Trần Đề & 0.061 & -2.859 & 2.920 \\
\hline 34 & Gành Hào & 0.063 & -2.747 & 2.810 \\
\hline 35 & Rạch Giá & 0.063 & -0.367 & 0.430 \\
\hline 36 & Hòn Đá Bạc & -0.027 & -0.797 & 0.770 \\
\hline
\end{tabular}


- Độ chênh giữa $\mathrm{A} 0$ và $\pi 0$ tại các trạm quan trắc thủy triều tạm thời (thời gian đo 30 ngày đêm), được Đoàn 6 đo đạc từ năm 2001 đến năm 2011 cho các khu vực biển được thống kê trong bảng 2 .

Bảng 2: Độ chênh A0 và $\pi 0$ tại các trạm nghiệm triều (Nguồn [3])

\begin{tabular}{|c|c|c|c|}
\hline Stt & Tên trạm & Năm đo & Độ chênh đo A0- $\pi 0$ (m) \\
\hline \multicolumn{4}{|c|}{ a. Trạm tham gia xây dựng mô hình } \\
\hline 1 & Sông Cầu & 2001 & 1.275 \\
\hline 2 & Phan Rí & 2004 & 1.97 \\
\hline 3 & Định An & 2006 & 2.66 \\
\hline 4 & Lại Sơn & 2004 & 0.50 \\
\hline 5 & Cọc 5 Quảng Ninh & 2007 & 2.17 \\
\hline 6 & Vạn Hoa, Quảng Ninh & 2008 & 2.42 \\
\hline 7 & An Bang & 2001 & 1.278 \\
\hline 8 & Phúc Nguyên & 2007 & 1.13 \\
\hline 9 & Tư Chính & 2007 & 1.13 \\
\hline 10 & Quế Đường & 2006 & 1.13 \\
\hline 11 & Ba kè & 2005 & 1.17 \\
\hline 12 & Sa Huỳnh & 2004 & 1.18 \\
\hline 13 & Cố Lũy & 2004 & 1.12 \\
\hline 14 & Mũi né & 2004 & 1.95 \\
\hline 15 & Cố Chiên & 2006 & 2.50 \\
\hline 16 & Bồ Đề & 2004 & 2.68 \\
\hline 17 & Nam Du & 2004 & 0.50 \\
\hline 18 & Hòn Tre & 2004 & 0.57 \\
\hline 19 & Hòn Hèo & 2004 & 0.57 \\
\hline 20 & Ngọc Vừng & 2007 & 2.28 \\
\hline 21 & Vĩnh Thực & 2008 & 2.39 \\
\hline 22 & Đá Lát & 2004 & 1.14 \\
\hline 23 & Đá Lớn & 2004 & 0.98 \\
\hline 24 & Tốc Tan & 2002 & 1.00 \\
\hline 25 & Núi Thị & 2004 & 0.94 \\
\hline 26 & Cô Lin & 2004 & 0.99 \\
\hline 27 & Trường Sa Lớn & 2009 & 1.18 \\
\hline 28 & Song Tử Tây & 2009 & 1.04 \\
\hline 29 & Nam Yết & 2009 & 0.93 \\
\hline \multicolumn{4}{|c|}{ b. Trạm kiểm tra } \\
\hline 30 & Cảng Vùng 3, Quy Nhơn & 2008 & 1.23 \\
\hline 31 & Sa Kỳ & 2004 & 1.12 \\
\hline 32 & Phú Quý & 2004 & 1.55 \\
\hline 33 & Côn Sơn & 2007 & 2.49 \\
\hline 34 & Gành Hào & 2004 & 2.68 \\
\hline 35 & Cầu Cảng BP S.Ông Đốc & 2001 & 0.695 \\
\hline 36 & Cửa Ông & 2007 & 2.17 \\
\hline 37 & Cát Bà & 2006 & 2.02 \\
\hline 38 & Cô Tô & 2008 & 2.18 \\
\hline 39 & Trạm Cửa hội & 2008 & 1.71 \\
\hline 40 & Quy Nhơn & 2008 & 1.23 \\
\hline 41 & Cảng Nha Trang & 2008 & 1.22 \\
\hline
\end{tabular}




\begin{tabular}{|l|c|c|c|}
\hline 42 & Cam Ranh & 2008 & 1.29 \\
\hline 43 & Thuận An & 2005 & 0.38 \\
\hline 44 & Cầu Cảng BP, Ninh Chữ & 2010 & 1.358 \\
\hline 45 & Cầu Cảng Phan Rí Cửa & 2010 & 1.772 \\
\hline 46 & Tân Cảng Quy Nhơn & 2010 & 0.731 \\
\hline 47 & Cảng Cửa Việt & 2011 & 0.522 \\
\hline 48 & Cửa Nhật Lệ & 2011 & 0.774 \\
\hline 49 & Cảng 2, Vùng 3 Đà Nẵng & 2011 & 0.766 \\
\hline 50 & Cảng Đông Tác, Đà Giang & 2010 & 1.166 \\
\hline 51 & Đá Nam & 2004 & 0.98 \\
\hline 52 & Phúc Tần & 2006 & 1.13 \\
\hline
\end{tabular}

b. Xây dưng mô hình mặt biển trung bình khu vục

Kết quả nghiên cứu của công trình [4] đã xác định được thế trọng trường của mặt geoid cục bộ sát nhất với mặt biển trung bình nhiều năm tại trạm nghiệm triều Hòn Dấu $W_{0}=62636847.2911 m^{2} \cdot s^{-2}$ và khoảng cách không đổi giữa mặt geoid cục bộ Hòn Dấu và mặt geoid toàn cầu $H_{0}=\frac{\overline{W_{0}}-W_{0}}{\bar{\gamma}_{0}}=0.890 \mathrm{~m}$, với $\overline{W_{0}}$ thế trọng trường của mặt geoid toàn cầu, $\bar{\gamma}_{0}$ là giá trị trung bình của gia tốc lực trọng trường chuẩn tại trạm nghiệm triều Hòn Dấu. Sử dụng 02 giá trị này để tính chuyển các giá trị $\overline{M D T}$ từ đỉnh các ô chuẩn CSDL của mô hỉnh DTU10MDT quốc tế tương ứng với mặt geoid toàn cầu về các giá trị MDT cục bộ tương ứng với mặt geoid cục bộ Hòn Dấu theo công thức [5]:

$$
\operatorname{MDTVN}_{m}=\overline{M D T_{n}}-0.890 m+\delta M D T_{n-m}+\left\{\begin{array}{l}
0 \quad k h i B \geq 19^{0} 57^{\prime} \\
-0.318 m \text { khi } B<19^{0} 57^{\prime}
\end{array}\right.
$$

trong đó:

* $\delta M D T_{n-m}$ là số cải chính chuyển giá trị $\overline{M D T_{n}}$ từ hệ không phụ thuộc triều về hệ triều trung bình và được xác định theo công thức:

$$
\delta M D T_{n-m}=0.033-0.0998 \sin ^{2} B(m)
$$

với $\mathrm{B}$ là vĩ độ trắc địa của đỉnh ô chuẩn tương ứng với ellipsoid WGS84 quốc tế;

* $-0.318 m$ là số hiệu chỉnh sai số hệ thống của các giá trị $\overline{M D T_{n}}$ từ mô hình DTU10MDT quốc tế cho vùng biển có vĩ độ $B<19^{\circ} 57^{\prime}$.

Bằng cách như vậy chúng ta đã chuyển được các giá trị $\overline{M D T_{n}}$ từ đỉnh các ô chuẩn CSDL của mô hình DTU10MDT quốc tế tương ứng với mặt geoid toàn cầu về các giá trị $M D T V N$ cục bộ tương ứng với mặt geoid cục bộ Hòn Dấu trong hệ triều trung bình.

Theo đánh giá trong [5], mô hình $M D T V N$ có độ chính xác rất cao và không cần làm khớp với các độ cao chuẩn của mặt biển trung bình trên các trạm nghiệm triều. Tuy nhiên, độ cao chuẩn của mặt biển trung bình trên 36 trạm nghiệm triều (xem hình 1a) trong [5] được đo đạc, tính toán tuân thủ nghiêm ngặt theo các quy định kỹ thuật hiện hành, đặc biệt là số liệu nghiệm triều tại 22 trạm 
tạm thời được đo nối vào thời gian nước cường để đảm bảo tính chính xác của kết quả, còn trong thực tế các trạm nghiệm triều tạm thời được quan trắc vào thời điểm đang tiến hành thi công công trình nên trong kết quả vẫn chứa một nguồn sai số đáng kể. Để giảm bớt rủi ro, chúng tôi tiến hành làm khớp mô hình $M D T V N$ với độ cao của các mặt biển trung bình trên 36 trạm nghiệm triều trong hệ triều trung bình (xem bảng 1) bằng Thuật toán loang (Spline with barriers) trong phần mềm ArcGIS. Kết quả chúng ta nhận được mô hình mặt biển trung bình khu vực $(M D T T B K V)$ phù hợp với độ cao của các mặt biển trung bình trên 36 trạm nghiệm triều (xem hình 2).

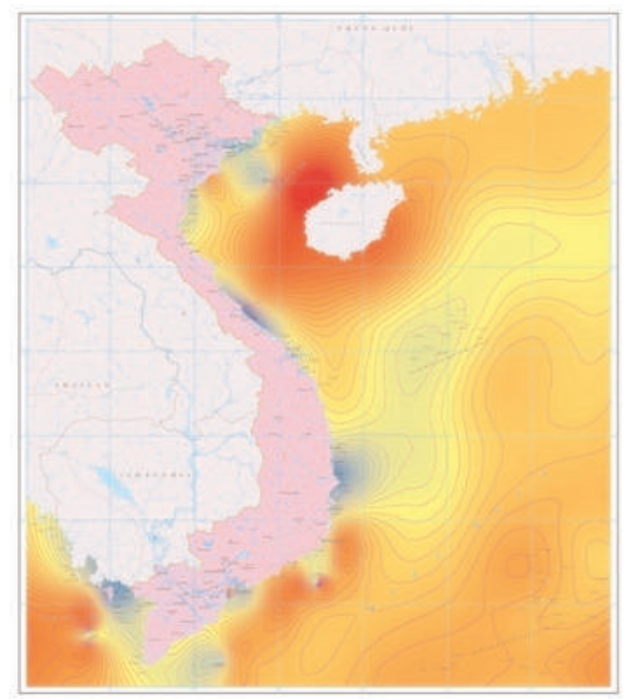

Hình 2: Hình ảnh của mô hình MDTTBKV trên vùng biển Việt Nam

Cấu trúc thông tin của một đỉnh của mạng lưới (grid) các ô chuẩn hình vuông với độ phân giải 1 ' x 1' của CSDL $M D T T B K V$ bao gồm các giá trị $L, B, M D T T B K V$ với kinh độ trắc địa $L$ và vĩ độ trắc địa $B$ được xác định trong hệ tọa độ WGS84 quốc tế. Mạng lưới (grid) các ô chuẩn hình vuông với độ phân giải $1^{\prime} \mathrm{x} 1^{\prime}$ ' có các đỉnh của các ô chuẩn hình vuông bắt đầu từ vĩ tuyến $24^{\circ}$ thay đổi với bước nhảy $\Delta B=1^{\prime}$ cho đến vĩ tuyến $7^{\circ}$. Tại một vĩ tuyến xác định, các đỉnh lại được bố trí theo kinh tuyến bắt đầu từ kinh tuyến $100^{\circ}$ thay đổi với bước nhảy $\Delta L=1^{\prime}$ cho đến kinh tuyến $116^{\circ}$. Các đỉnh nằm trong đất liền có giá trị $M D T V N$ bằng 0 . Trong phạm vi Biển Đông bao trùm vùng biển Việt Nam có tất cả 18.109 đỉnh của các ô chuẩn. Các dữ liệu trên một đỉnh của ô chuẩn hình vuông bao gồm: giá trị $L, B, M D T V N K V$, ở đây kinh độ trắc địa $L$ và vĩ độ trắc địa $B$ được xác định trong hệ tọa độ WGS84 quốc tế.

\section{c. Xây dựng mô hình mặt biển thấp nhất khu vực}

Theo khẳng định trong [5], phụ thuộc vào chế độ thủy triều, chế độ gió, độ dốc của địa hình,... mối quan hệ giữa mặt biển thấp nhất và mặt biển trung bình tại các trạm nghiệm triều khác nhau là khác nhau. Do đó, không thể thiết lập được các mối quan hệ toán học giữa các độ chênh của mặt biển thấp nhất so với mặt biển trung bình được xác định tại các trạm nghiệm triều trên toàn bộ vùng biển Việt Nam. Vì lý do này, chúng ta không thể dựa vào mô hình $M D T T B K V$ để xây dựng mô hình mặt biển thấp nhất trên vùng biển Việt Nam. Như vậy, việc xây dựng các mô hình mặt biển thấp nhất trên vùng biển Việt Nam được thực hiện nhờ các điểm đặc trưng là các giá trị độ cao nhà nước của các mực nước thấp nhất được xác định trên các trạm nghiệm triều thuộc vùng biển Việt Nam. Việc thành lập mô hình mặt biển thấp nhất được thực hiện tương tự như việc xây dựng mô hình số địa 
hình trên đất liền nhờ phần mềm ArcGIS.

Dựa trên độ cao trong hệ triều trung bình của mặt biển thấp nhất tại 36 trạm nghiệm triều trong bảng 1 và phần mềm ArcMap và ArcCatalog của hãng ESRI, chúng ta xây dựng được mô hình mặt biển thấp nhất khu vực (gọi là mô hình $M B T N K V 36$ ) trên vùng biển Việt Nam.

\section{d. Đánh giá độ chính xác độ chênh giũa mô hình MDTTBKV và mô hình MBTNKV36}

Do mặt chuẩn độ sâu để quy chiếu các trị đo sâu địa hình đáy biển được xác định dựa vào số "0" hải đồ khu vực, nên trong công tác đo đạc thành lập hải đồ người ta chỉ tính toán xác định độ chênh giữa mặt biển trung bình và mặt biển thấp nhất tại khu vực thi công để quy chiếu độ sâu từ mặt biển trung bình về mặt biển thấp nhất (sau khi đã hiệu chỉnh ảnh hưởng của thủy triều). Phần lớn các trạm quan trắc thủy triều phục vụ xử lý số liệu đo sâu để thành lập hải đồ đều không được đo nối với hệ độ cao quốc gia. Vì vậy, mặt biển trung bình và mặt biển thấp tại các trạm nghiệm triều phục vụ công tác thành lập hải đồ không có giá trị độ cao trong hệ độ cao quốc gia HP72.

Dựa trên 02 mô hình $M D T T B K V$ và $M B T N K V 36$ vừa xây dựng, chúng ta có thể xác định độ chênh giữa $M D T T B K V$ và $M B T N K V 36$ (chênh cao giữa $\mathrm{A} 0$ và $\pi 0$ ) cho mọi vị trí. Vì vậy, trong bài báo này đã sử dụng các độ chênh giữa $\mathrm{A} 0$ và $\pi 0$ theo mô hình và độ chênh giữa $\mathrm{A} 0$ và $\pi 0$ trên các trạm nghiệm triều do Đoàn 6 đo đạc từ năm 2000 đến năm 2011 (xem bảng 3 ) để đánh giá độ chính xác của 02 mô hình nêu trên. Kết quả đánh giá độ chính xác độ chênh giữa 02 mô hình được thể hiện trong bảng 3 .

Bảng 3: Kết quả đánh giá độ chính xác độ chênh giũa mô hình MDTTBKV và mô hình MBTNKV36

\begin{tabular}{|c|c|c|c|c|c|c|c|}
\hline STT & Tên trạm & $\begin{array}{l}\text { Năm } \\
\text { đo }\end{array}$ & $\begin{array}{c}\text { A } 0-\pi 0 \\
\text { đo }(\mathrm{m})\end{array}$ & $\begin{array}{c}\text { Độcao } \\
\operatorname{MDTTBKV}(\mathrm{m})\end{array}$ & $\begin{array}{c}\text { Đô cao } \\
M B T N K V 36(m)\end{array}$ & $\begin{array}{c}\mathrm{A} 0-\pi 0 \\
\text { tính }(\mathrm{m})\end{array}$ & $d_{i}=(7)-(4)$ \\
\hline (1) & (2) & (3) & (4) & $(5)$ & $(6)$ & (7) & (8) \\
\hline 1 & Cửa Ông & 2001 & 1.23 & -0.006 & -0.970 & 0.964 & -0.266 \\
\hline 2 & Cát Bà & 2004 & 1.12 & 0.094 & -0.809 & 0.903 & -0.217 \\
\hline 3 & Cô Tô & 2006 & 1.55 & 0.138 & -1.099 & 1.237 & -0.313 \\
\hline 4 & Trạm Cửa hội & 2004 & 2.49 & -0.048 & -2.280 & 2.232 & -0.258 \\
\hline 5 & Quy Nhơn & 2007 & 2.68 & 0.064 & -2.841 & 2.905 & 0.225 \\
\hline 6 & Cảng Nha Trang & 2008 & 0.695 & -0.026 & -0.812 & 0.786 & 0.091 \\
\hline 7 & Cam Ranh & 2001 & 2.17 & -0.001 & -2.124 & 2.122 & -0.048 \\
\hline 8 & Thuận An & 2007 & 2.02 & -0.064 & -2.138 & 2.074 & 0.054 \\
\hline 9 & Cầu Cảng BP, Ninh Chữ & 2007 & 2.18 & 0.112 & -1.980 & 2.092 & -0.088 \\
\hline 10 & Cầu Cảng Phan Rí Cửa & 2006 & 1.71 & -0.063 & -2.071 & 2.008 & 0.298 \\
\hline 11 & Tân Cảng Quy Nhơn & 2005 & 1.23 & -0.013 & -0.974 & 0.961 & -0.269 \\
\hline 12 & Cảng Cửa Việt & 2008 & 1.22 & -0.041 & -0.978 & 0.937 & -0.283 \\
\hline 13 & Cửa Nhật Lệ & 2004 & 1.29 & 0.106 & -1.063 & 1.170 & -0.120 \\
\hline 14 & Cảng 2, Vùng 3 Đà Nẵng & 2004 & 0.38 & -0.174 & -0.450 & 0.276 & -0.104 \\
\hline 15 & Cảng Đông Tác, Đà Giang & 2007 & 1.358 & -0.004 & -1.129 & 1.126 & -0.232 \\
\hline 16 & Đá Nam & 2004 & 1.7719 & 0.035 & -1.281 & 1.316 & -0.456 \\
\hline 17 & Phúc Tần & 2001 & 0.7306 & -0.024 & -0.897 & 0.874 & 0.143 \\
\hline 18 & Sông Cầu & 2007 & 0.522 & -0.284 & -0.690 & 0.407 & -0.115 \\
\hline 19 & Phan Rí & 2006 & 0.774 & -0.068 & -1.137 & 1.070 & 0.296 \\
\hline 20 & Định An & 2008 & 0.766 & 0.030 & -0.654 & 0.684 & -0.082 \\
\hline
\end{tabular}




\begin{tabular}{|l|c|c|c|c|c|c|c|}
\hline 21 & Lại Sơn & 2008 & 1.166 & -0.240 & -1.026 & 0.786 & -0.380 \\
\hline 22 & Cọc 5 Quảng Ninh & 2008 & 0.98 & 0.197 & -0.781 & 0.978 & -0.002 \\
\hline 23 & Vạn Hoa, Quảng Ninh & 2008 & 1.13 & 0.210 & -1.273 & 1.482 & 0.352 \\
\hline 24 & An Bang & 2008 & 1.275 & -0.098 & -0.974 & 0.876 & -0.399 \\
\hline 25 & Phúc Nguyên & 2005 & 1.97 & 0.035 & -1.281 & 1.316 & -0.654 \\
\hline 26 & Tư Chính & 2010 & 2.66 & 0.086 & -2.873 & 2.959 & 0.299 \\
\hline 27 & Quế Đường & 2010 & 0.50 & -0.051 & -0.219 & 0.167 & -0.333 \\
\hline 28 & Ba kè & 2010 & 2.17 & -0.058 & -2.283 & 2.225 & 0.055 \\
\hline 29 & Sa Huỳnh & 2011 & 2.42 & 0.045 & -2.222 & 2.267 & -0.153 \\
\hline 30 & Cổ Lũy & 2011 & 1.278 & 0.196 & -1.202 & 1.398 & 0.120 \\
\hline 31 & Mũi né & 2011 & 1.13 & 0.193 & -1.390 & 1.583 & 0.453 \\
\hline 32 & Cổ Chiên & 2010 & 1.13 & 0.190 & -1.561 & 1.751 & 0.621 \\
\hline 33 & Bồ Đề & 2004 & 1.13 & 0.210 & -1.318 & 1.529 & 0.399 \\
\hline 34 & Nam Du & 2004 & 1.17 & 0.214 & -1.239 & 1.453 & 0.283 \\
\hline 35 & Hòn Tre & 2004 & 1.18 & 0.074 & -0.870 & 0.945 & -0.235 \\
\hline 36 & Hòn Hèo & 2006 & 1.12 & 0.088 & -0.828 & 0.916 & -0.204 \\
\hline 37 & Ngọc Vừng & 2004 & 1.95 & 0.141 & -1.467 & 1.607 & -0.343 \\
\hline 38 & Vĩnh Thực & 2004 & 2.50 & 0.091 & -2.835 & 2.926 & 0.426 \\
\hline 39 & Đá Lát & 2004 & 2.68 & 0.027 & -2.190 & 2.217 & -0.463 \\
\hline 40 & Đá Lớn & 2004 & 0.5 & -0.063 & -0.193 & 0.130 & -0.370 \\
\hline 41 & Tốc Tan & 2006 & 0.57 & -0.004 & -0.263 & 0.259 & -0.311 \\
\hline 42 & Núi Thị & 2007 & 0.57 & -0.132 & -0.293 & 0.162 & -0.408 \\
\hline 43 & Cô Lin & 2008 & 2.28 & -0.016 & -2.085 & 2.070 & -0.210 \\
\hline 44 & Trường Sa Lớn & 2004 & 2.39 & 0.058 & -2.490 & 2.548 & 0.158 \\
\hline 45 & Song Tử Tây & 2004 & 1.14 & 0.215 & -1.162 & 1.377 & 0.237 \\
\hline 46 & Nam Yết & 2004 & 0.98 & 0.195 & -0.946 & 1.141 & 0.161 \\
\hline 47 & Cửa Ông & 2002 & 1.00 & 0.195 & -1.075 & 1.270 & 0.270 \\
\hline 48 & Cát Bà & 2004 & 0.94 & 0.182 & -0.887 & 1.070 & 0.130 \\
\hline 49 & Cô Tô & 2004 & 0.99 & 0.180 & -0.969 & 1.149 & 0.159 \\
\hline 50 & Trạm Cửa hội & 2009 & 1.18 & 0.212 & -1.141 & 1.353 & 0.173 \\
\hline 51 & Quy Nhơn & 2009 & 1.04 & 0.201 & -0.791 & 0.992 & -0.048 \\
\hline 52 & Cảng Nha Trang & 2009 & 0.93 & 0.188 & -0.919 & 1.107 & 0.177 \\
\hline & & & & & & 2 & -1.786 \\
\hline & & & & & & \\
\hline 37 & & & & \\
\hline
\end{tabular}

Kết quả kiểm tra sai số hệ thống

$$
A=\sum_{i=l}^{52} d_{i}=-1.786 m, B=\sum_{i=l}^{52}\left|d_{i}\right|=12.943 \mathrm{~m} .
$$

Do $|A|=1.786<0.25 . B=3.236$ nên trong hai dãy các giá trị độ chênh (A0- $\pi 0)$ không chứa sai số hệ thống. Khi coi các độ chênh ( $\mathrm{A} 0$ - $\pi 0$ tính theo mô hình) và (A0- $\pi 0$ đo) là hai dãy trị đo kép độc lập cùng độ chính xác, chúng ta đánh giá độ chính xác độ chênh giữa mô hình $M D T T B K V$ và mô hình MBTNKV36 theo công thức:

$$
m_{(a 0-\pi 0)}= \pm \sqrt{\frac{\sum_{i=1}^{52} d_{i}^{2}}{2.52}}= \pm \sqrt{\frac{4.276}{104}}= \pm 0.203 \mathrm{~m} .
$$


Như vậy, với tiêu chí xác định mặt biển trung bình tại trạm nghiệm triều tạm thời theo số liệu đo mực nước biển liên tục trong 30 ngày đêm với sai số trung phương ở mức $\pm 0.3 \mathrm{~m}$ [1], chúng ta có thể kết luận rằng các mô hình $M D T T B K V$ và $M B T N K V 36$ được xác định với độ chính xác khá cao.

\section{e. Hoàn chỉnh mô hình mặt biển thấp nhất khu vục}

Trên cơ sở kết quả đánh giá độ chính xác ở trên ta nhận thấy rằng, các mô hình $M D T T B K V$ và $M B T N K V 36$ có thể đưa vào thử nghiệm để tính toán các trị đo sâu dựa trên mặt biển trung bình khu vực để thành lập bản đồ địa hình đáy biển hay tính toán các trị đo sâu dựa trên mặt biển thấp nhất khu vực để thành lập hải đồ. Nhằm tăng cường độ chính xác của mô hình $M B T N K V 36$, chúng tôi lựa chọn thêm 29 điểm có độ chênh giữa mặt biển trung bình khu vực và mặt biển thấp nhất khu vực của Đoàn 6 , đặc biệt là các điểm trên quần đảo Trường Sa (các điểm có số thứ tự từ 1 đến 29 trong bảng 2 và được thể hiện bằng màu vàng trên hình $1 \mathrm{~b}$ ), kết hợp với 36 điểm có độ cao mặt biển thấp nhất trong bảng 1 (cột 5) để xây dựng mô hình $M B T N K V$ (gọi là mô hình $M B T B K V 65$ ). Do mô hình $M D T T B K V$ được xây dựng từ CSDL của mô hình DTU10MDT có độ chính xác rất cao trên toàn Biển Đông và được làm khớp với các mặt biển trung bình khu vực tại 36 trạm nghiệm triều dọc bờ biển và trên một số đảo của Việt Nam, nên từ các độ chênh so với $M D T T B K V$ chúng ta xác định được độ cao mặt biển thấp nhất khu vực tại 29 trạm nghiệm triều tạm thời này. Quy trình xây dựng mô hình MBTNKV65 hoàn toàn tương tự như xây dựng mô hình MBTNKV36 và kết quả được thể hiện trên hình 3 .

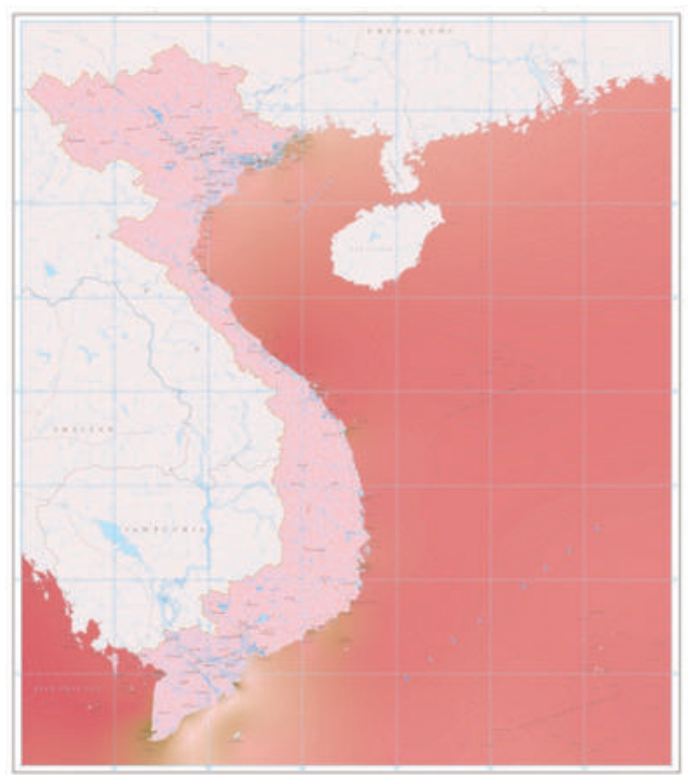

Hình 3: Hình ảnh của mô hình MBTNKV65 trên vùng biển Việt Nam

Cơ sở dữ liệu của mô hình mô hình $M B T N K V 65$ trên vùng biển Việt Nam là mạng lưới (grid) các ô chuẩn hình vuông với độ phân giải $1^{\prime} \mathrm{x} 1^{\prime}$ có các đỉnh của các ô chuẩn hình vuông bắt đầu từ vĩ tuyến $24^{\circ}$ thay đổi với bước nhảy $\Delta B=1^{\prime}$ cho đến vĩ tuyến $7^{\circ}$. Tại một vĩ tuyến xác định, các đỉnh lại được bố trí theo kinh tuyến bắt đầu từ kinh tuyến $100^{\circ}$ thay đổi với bước nhảy $\Delta L=1^{\prime}$ cho đến kinh tuyến $116^{\circ}$. Trong phạm vi Biển Đông bao trùm vùng biển Việt Nam có tất cả 18.109 đỉnh của các ô chuẩn. Các dữ liệu trên một đỉnh của ô chuẩn hình vuông bao gồm: giá trị $\mathrm{L}, \mathrm{B}, M B T N K V 65$ ở đây kinh độ trắc địa $\mathrm{L}$ và vĩ độ trắc địa $\mathrm{B}$ được xác định trong hệ tọa độ WGS84 quốc tế. 


\section{f. Đánh giá độ chính xác độ chênh giũa giữa mô hình MDTTBKV và mô hình MBTNKV65}

Sử dụng 23 điểm có độ chênh đo giữa mặt biển trung bình và mặt biển thấp nhất khu vực của Đoàn 6 không tham gia xây dựng mô hình MBTNKV65 (các điểm có số thứ tự từ 30 đến 52 trong bảng 2 và được thể hiện bằng màu trắng trên hình $1 \mathrm{~b}$ ) để đánh giá độ chính xác của độ chênh giữa mô hình $M D T T B K V$ và mô hình $M B T N K V 65$. Kết quả tính toán để đánh giá độ chính xác độ chênh giữa mô hình $M D T T B K V$ và mô hình $M B T N K V 65$ thể hiện trong bảng 4.

Bảng 4: Kết quả đánh giá độ chính xác độ chênh giũa mô hình MDTTBKV và mô hình MBTNKV65

\begin{tabular}{|c|c|c|c|c|c|c|c|}
\hline STT & Tên trạm & $\begin{array}{l}\text { Năm } \\
\text { đo }\end{array}$ & $\begin{array}{c}\text { A0 }-\pi 0 \\
\text { đo }(\mathrm{m})\end{array}$ & $\operatorname{MDTTBKV}(\mathrm{m})$ & MBTNKH65 (m) & $\begin{array}{c}\mathrm{A} 0-\pi 0 \\
\text { tính }(\mathrm{m})\end{array}$ & $d_{i}=(7)-(4)$ \\
\hline 1 & Cảng Vùng 3 - Quy Nhơn & 2008 & 1.23 & -0.006 & -0.970 & 0.964 & -0.266 \\
\hline 2 & Sa Kỳ & 2004 & 1.12 & 0.094 & -0.814 & 0.909 & -0.211 \\
\hline 3 & Phú Quý & 2004 & 1.55 & 0.138 & -1.081 & 1.219 & -0.331 \\
\hline 4 & Côn Sơn & 2007 & 2.49 & -0.048 & -2.280 & 2.232 & -0.258 \\
\hline 5 & Gành Hào & 2004 & 2.68 & 0.064 & -2.836 & 2.900 & 0.220 \\
\hline 6 & Cầu Cảng BP S. Ông Đốc & 2001 & 0.695 & -0.026 & -0.817 & 0.791 & 0.096 \\
\hline 7 & Cửa Ông & 2007 & 2.17 & -0.001 & -2.142 & 2.141 & -0.029 \\
\hline 8 & Cát Bà & 2006 & 2.02 & -0.064 & -2.187 & 2.123 & 0.103 \\
\hline 9 & Cô Tô & 2008 & 2.18 & 0.112 & -1.986 & 2.098 & -0.082 \\
\hline 10 & Trạm Cửa hội & 2008 & 1.71 & -0.063 & -2.074 & 2.011 & 0.301 \\
\hline 11 & Quy Nhơn & 2008 & 1.23 & -0.013 & -0.971 & 0.958 & -0.272 \\
\hline 12 & Cảng Nha Trang & 2008 & 1.22 & -0.041 & -0.992 & 0.951 & -0.269 \\
\hline 13 & Cam Ranh & 2008 & 1.29 & 0.106 & -1.038 & 1.144 & -0.146 \\
\hline 14 & Thuận An & 2005 & 0.38 & -0.174 & -0.450 & 0.276 & -0.104 \\
\hline 15 & Cầu Cảng BP, Ninh Chữ & 2010 & 1.358 & -0.004 & -1.104 & 1.100 & -0.258 \\
\hline 16 & Cầu Cảng Phan Rí Cửa & 2010 & 1.7719 & 0.035 & -1.952 & 1.986 & 0.214 \\
\hline 17 & Tân Cảng Quy Nhơn & 2010 & 0.7306 & -0.024 & -0.948 & 0.924 & 0.193 \\
\hline 18 & Cảng Cửa Việt & 2011 & 0.522 & -0.284 & -0.690 & 0.407 & -0.115 \\
\hline 19 & Cửa Nhật Lệ & 2011 & 0.774 & -0.068 & -1.137 & 1.069 & 0.295 \\
\hline 20 & Cảng 2, Vùng 3 Đà Nẵng & 2011 & 0.766 & 0.030 & -0.653 & 0.683 & -0.083 \\
\hline 21 & Cảng Đông Tác, Đà Giang & 2010 & 1.166 & -0.240 & -1.031 & 0.791 & -0.375 \\
\hline 22 & Đá Nam & 2006 & 0.98 & 0.197 & -1.042 & 1.238 & 0.258 \\
\hline \multirow[t]{2}{*}{23} & Phúc Tần & 2004 & 1.13 & 0.210 & -1.113 & 1.322 & 0.192 \\
\hline & & & & & & $E_{i}=$ & -0.925 \\
\hline
\end{tabular}

Kết quả kiểm tra sai số hệ thống

$$
A=\sum_{i=1}^{23} d_{i}=-0.925 m, B=\sum_{i=I}^{23}\left|d_{i}\right|=4.674 m .
$$

Do $|A|=0.925<0.25 . B=1.168$ nên trong hai dãy giá trị độ chênh (A0- $\pi 0)$ không chứa sai số hệ thống. Khi coi các độ chênh ( $\mathrm{A} 0$ - $\pi 0$ tính theo mô hình) và (A0- $\pi 0$ đo) là hai dãy trị đo kép độc lập cùng độ chính xác, chúng ta đánh giá độ chính xác độ chênh giữa mô hình $M D T T B K V$ và mô hình MBTNKV65 theo công thức: 


$$
m_{(\mathrm{A} 0-\pi 0)}= \pm \sqrt{\frac{\sum_{i=l}^{23} d_{i}^{2}}{2.23}}= \pm \sqrt{\frac{1.138}{46}}= \pm 0.157 \mathrm{~m} .
$$

Như vậy, với tiêu chí xác định mặt biên trung bình tại trạm nghiệm triêu tạm thời theo sô liệu đo mực nước biển liên tục trong 30 ngày đêm với sai số trung phương ở mức $\pm 0.3 \mathrm{~m}$, chúng ta có thể kết luận rằng các mô hình $M D T T B K V$ và $M B T N K V 65$ được xác định với độ chính xác rất cao.

\section{g. Đánh giá kết quả quy chiếu độ sâu để thành lập hải đồ}

Để khẳng định giá trị của hai mô hình $M D T T B K V$ và $M B T N K H 65$ mới được xây dựng, chúng tôi tính toán thử nghiệm độ sâu địa hình đáy biển để thành lập hải đồ bằng hai phương án: Tính toán độ sâu hải đồ sử dụng độ chênh giữa mặt biển trung bình và mặt biển thấp nhất theo số liệu quan trắc tại trạm nghiệm triều tạm thời ven bờ biển và tính toán dựa vào hai mô hình $M D T T B K V$ và MBTNKH65.

Mảnh hải đồ thử nghiệm là IA- IA-25-(20+21) do Đoàn 6 đo đạc năm 1994, tỷ lệ 1:100.000 bao phủ vùng biển từ cửa Lục đến cửa $B a$ Lạt với 3.687 điểm đo sâu. Số liệu đo sâu sau khi tính cải chính thủy triều sẽ quy chiếu về mặt chuẩn " 0 " độ sâu hải đồ bằng cách trừ đi độ chênh $\Delta \mathrm{B}$ (= $\mathrm{A} 0$ $\pi 0$ ) giữa mặt biển trung bình và mặt biển thấp nhất theo số liệu quan trắc tại trạm nghiệm triều của

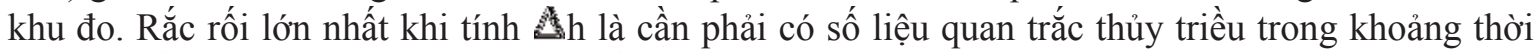
gian ít nhất 30 ngày tại trạm nghiệm triều tạm thời. Phương pháp thứ hai là căn cứ vào tọa độ vị trí

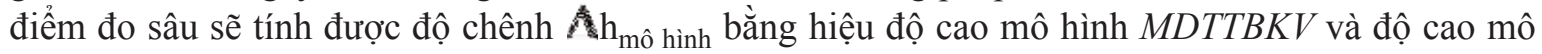
hình $M B T B K V 65$. Dựa vào giá trị $\mathrm{h}_{\mathrm{m}}$ hình để quy chiếu số liệu đo độ sâu về mặt chuẩn "0" độ sâu hải đồ. Kết quả tính toán bằng hai phương pháp được thể hiện trong bảng 5 .

Bảng 5: Đánh giá kết quả quy chiếu độ sâu để thành lập hải đồ

\begin{tabular}{|c|c|c|c|c|c|c|c|c|}
\hline STT & $\begin{array}{c}\text { Độ sâu đo (đã } \\
\text { cải chính thủy } \\
\text { triều }(\mathrm{m})\end{array}$ & 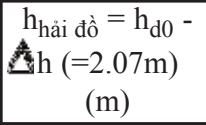 & $\begin{array}{c}\mathrm{A} 0 \\
\left(\mathrm{~h}_{M D T T B K V}\right) \\
(\mathrm{m})\end{array}$ & $\begin{array}{c}\pi 0 \\
\left(\mathrm{~h}_{M B T N K V 65}\right) \\
(\mathrm{m})\end{array}$ & $\begin{array}{c}\text { Độ chênh } \\
(\mathrm{A} 0-\pi 0) \\
(\mathrm{m})\end{array}$ & $\begin{array}{l}\mathrm{h}_{\text {hải đồ }} \\
\text { tính (m) }\end{array}$ & $\begin{array}{c}\text { Độ lệch } \\
\text { di=(7)-(2) } \\
\text { (m) }\end{array}$ & $\varepsilon=\mathrm{d}_{\mathrm{i}}-\delta_{\mathrm{tb}}$ \\
\hline (1) & (2) & (3) & (4) & (5) & (6) & (7) & (8) & (9) \\
\hline 1 & 1.87 & -0.2 & 0.05 & -2.15 & 2.20 & -0.33 & 0.13 & 0.07 \\
\hline 2 & 1.97 & -0.1 & 0.05 & -2.15 & 2.20 & -0.23 & 0.13 & 0.07 \\
\hline 3 & 1.17 & -0.9 & 0.05 & -2.15 & 2.20 & -1.03 & 0.13 & 0.07 \\
\hline 4 & 1.17 & -0.9 & 0.06 & -2.15 & 2.21 & -1.04 & 0.14 & 0.08 \\
\hline 5 & 0.97 & -1.1 & 0.05 & -2.15 & 2.20 & -1.23 & 0.13 & 0.07 \\
\hline 6 & 0.77 & -1.3 & 0.05 & -2.15 & 2.20 & -1.43 & 0.13 & 0.07 \\
\hline 7 & 1.47 & -0.6 & 0.05 & -2.15 & 2.21 & -0.74 & 0.14 & 0.08 \\
\hline 8 & 1.37 & -0.7 & 0.05 & -2.16 & 2.22 & -0.85 & 0.15 & 0.09 \\
\hline 9 & 1.47 & -0.6 & 0.05 & -2.15 & 2.21 & -0.74 & 0.14 & 0.08 \\
\hline$\ldots$ & $\ldots$ & $\ldots$ & $\ldots$ & $\ldots$ & $\ldots$ & $\ldots$ & $\ldots$ & $\ldots$ \\
\hline 1001 & 6.07 & 4.0 & -0.06 & -2.21 & 2.14 & 3.93 & 0.22 & 0.01 \\
\hline 1002 & 6.17 & 4.1 & -0.07 & -2.16 & 2.09 & 4.08 & 0.23 & -0.04 \\
\hline 1003 & 6.17 & 4.1 & -0.07 & -2.18 & 2.11 & 4.06 & 0.24 & -0.02 \\
\hline 1004 & 6.17 & 4.1 & 0.08 & -2.17 & 2.25 & 3.92 & 0.25 & 0.12 \\
\hline 1005 & 6.17 & 4.1 & -0.01 & -2.09 & 2.08 & 4.09 & 0.23 & -0.05 \\
\hline 1006 & 6.17 & 4.1 & -0.06 & -2.07 & 2.01 & 4.16 & 0.24 & -0.12 \\
\hline
\end{tabular}


Nghiên cứu

\begin{tabular}{|c|c|c|c|c|c|c|c|c|}
\hline 1007 & 6.17 & 4.1 & -0.05 & -2.16 & 2.11 & 4.06 & 0.24 & -0.02 \\
\hline 1008 & 6.27 & 4.2 & -0.09 & -2.25 & 2.16 & 4.11 & 0.24 & 0.03 \\
\hline 1009 & 6.27 & 4.2 & -0.07 & -2.18 & 2.11 & 4.16 & 0.25 & -0.02 \\
\hline$\ldots$ & $\ldots$ & $\ldots$ & $\ldots$ & $\ldots$ & $\ldots$ & $\ldots$ & $\ldots$ & $\ldots$ \\
\hline 3679 & 33.57 & 31.5 & -0.04 & -2.08 & 2.04 & 31.53 & -0.03 & -0.09 \\
\hline 3680 & 33.57 & 31.5 & -0.03 & -2.08 & 2.04 & 31.53 & -0.03 & -0.09 \\
\hline 3681 & 33.57 & 31.5 & -0.04 & -2.06 & 2.03 & 31.54 & -0.04 & -0.10 \\
\hline 3682 & 33.57 & 31.5 & -0.04 & -2.07 & 2.03 & 31.54 & -0.04 & -0.10 \\
\hline 3683 & 34.07 & 32 & -0.01 & -2.08 & 2.08 & 31.99 & 0.01 & -0.05 \\
\hline 3684 & 34.07 & 32 & -0.01 & -2.08 & 2.08 & 31.99 & 0.01 & -0.05 \\
\hline 3685 & 35.07 & 33 & -0.01 & -2.08 & 2.07 & 33.00 & 0.00 & -0.06 \\
\hline 3686 & 35.07 & 33 & -0.02 & -2.08 & 2.06 & 33.01 & -0.01 & -0.07 \\
\hline 3687 & 35.07 & 33 & -0.01 & -2.09 & 2.08 & 32.99 & 0.01 & -0.05 \\
\hline & & & & & & $\mathbf{E}=$ & 230.86 & 9.64 \\
\hline
\end{tabular}

Xem độ sâu hải đồ đo và độ sâu hải đồ tính theo mô hình là hai dãy trị đo độc lập với nhau và tiến hành đánh giá độ chính xác. Kết quả kiểm tra sai số hệ thống $A=\sum_{i=1}^{3687} d_{i}=230.86 m, B=\sum_{i=1}^{3687}\left|d_{i}\right|=262.49 \mathrm{~m}$. Do $|A|=230.86>0.25 . B=65.62$, nên trong hai dãy trị đo trên có chứa sai số hệ thống. Điều này là hiển nhiên vì với diện tích khu đo rộng hơn $6.000 \mathrm{~km}^{2}$ (phần biển) và đường bờ biển dài hơn 100 km nhưng chỉ sử dụng 01 trạm nghiệm triều ven bờ để hiệu chỉnh trị đo sâu. Trong khi đó, mặt biển trung bình ở các khu vực khác nhau sẽ không giống nhau. Tiến hành khử sai số hệ thống theo phương pháp Besel:

- Tính số hiệu chỉnh $\delta_{t b}$ theo công thức: $\delta_{t b}=\frac{[d]}{n}=0.06 m$

- Khử sai số hệ thống khỏi hiệu $\mathrm{d}_{\mathrm{i}}$ theo công thức: $\varepsilon_{i}=d_{i}-\delta_{t b}$

Kết quả kiểm tra sau khi khử sai số hệ thống, trong hiệu $d_{i}$ không còn chứa sai số hệ thống.

- Tính sai số trung phương theo công thức:

$$
m_{d s_{-} d c}= \pm \sqrt{\frac{[\varepsilon \varepsilon]}{2(n-1)}}=\sqrt{\frac{223.134}{2.3686}} \pm 0.174 m
$$

Trên cơ sở đánh giá độ chính xác kết quả tính độ sâu hải đồ theo phương pháp sử dụng độ chênh mặt biển trung bình và mặt biển thấp nhất theo số liệu quan trắc thủy triều tại một trạm ven bờ và sử dụng hai mô hình $M D T T B K V$ và $M B T N K V 65$, ta có thể kết luận rằng phương pháp sử dụng các mô hình hiệu quả hơn và cho kết quả tin cậy hơn. Trên hình 4 là kết quả trích một phần hải đồ được thành lập theo độ chênh mặt biển trung bình và mặt biển thấp nhất dựa trên số liệu quan trắc thủy triều của một trạm ven bờ (hình 4.a) và sử dụng hai mô hình $M D T T B K V$ và $M B T N K V 65$ (hình 4.b).

\section{Kết luận}

Các mô hình $M D T T B K V$ và $M B T N K V 65$ được thành lập theo phương pháp hiện đại dựa trên các số liệu hoàn toàn tin cậy. Kết quả đánh giá độ chính xác và thử nghiệm tính độ sâu hải đồ theo phương pháp sử dụng số liệu quan trắc thủy triều và sử dụng mô hình cho thấy, có thể sử dụng mô hình $M D T T B K V$ để quy chiếu các trị đo sâu trong công tác thành lập bản đồ địa hình đáy biển và xây dựng nền thông tin địa lý biển, còn mô hình MBTNKV65 hoàn toàn đảm bảo độ chính xác để quy chiếu các trị đo sâu trong công tác thành lập các loại hải đồ trên Biển Đông./.O 


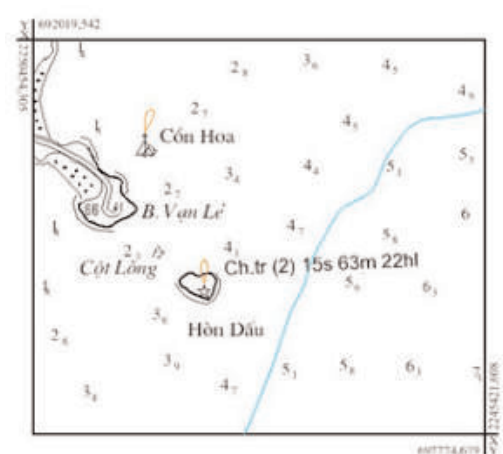

Hìn 4a: Hải đồ thành lập theo số liệu quan trắc thủy triều

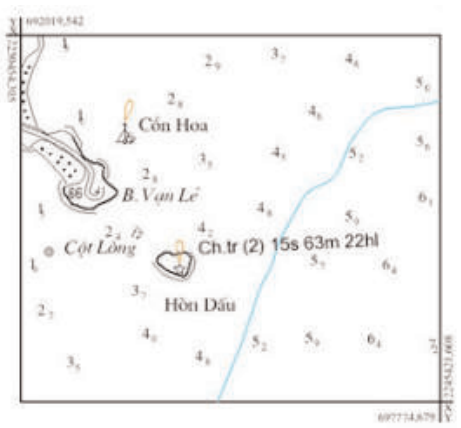

Hình 4b: Hải đồ thành lập theo số liệu của mô hình MDTTBKV và MBTNKV65

\section{Tài liệu tham khảo}

[1]. Bộ Tài nguyên Môi trường, (2006). Quy phạm quan trắc hải văn ven bờ. TCN số 21/2006/QĐ-BTNMT.

[2]. Cục Bản đồ, (2011). Trắc địa biển. NXB QĐND. Hà Nội-2011.

[3]. Đoàn Đo đạc Biên vẽ hải đồ và Nghiên cứu biển, (2009). Thông tin về hệ thống bản đồ biển. Hải Phòng-2009.

[4]. Hà Minh Hòa, (2012). Nghiên cứu cơ sở khoa học của việc hoàn thiện hệ độ cao gắn liền với việc xây dựng Hệ tọa độ động lực quốc gia. Báo cáo tổng hợp kết quả Đề tài NCKH cấp Bộ Tài nguyên và Môi trường. Viện Khoa học Đo đạc và Bản đồ.

[5]. Hà Minh Hòa, (2015). Nghiên cứu đánh giá các mặt chuẩn mực nước biển (mặt " 0 ” độ sâu, trung bình và cao nhất) theo các phương pháp trắc địa, hải văn và kiến tạo hiện đại phục vụ xây dựng các công trình và quy hoạch đới bờ Việt Nam trong xu thế biến đổi khí hậu. Báo cáo tổng hợp kết quả Đề tài NCKH cấp Nhà nước. Mã số KC.09.19/11-15. Bộ Khoa học và Công nghệ.

[6]. Nguyễn Ngọc Thủy, (1984). Thủy triều vùng biển Việt Nam, NXB KHKT, Hà Nội-1984.O

\section{Summary}

\section{Construction of middle East Sea models and the lowest sea area in the Vietnam sea area}

Khuong Van Long, Department of Maritime Mapping and Maritime Studies

Luong Thanh Thach, Hanoi University of Natural Resources and Environment

Tran Van Hai, Survey Enterprise, Survey and Aerial mapping one member Ltd. Company

Dang Xuan Thuy, Vietnam Institute of Geodesy and Cartography

East Sea is a defined as a highly complex tidal area, thus it is difficult to calculate and determine the standard surfaces for processing depth measurement data. At present, the average elevation of sea surface and sea surface is calcullated based on the tidal data with minimum monitoring time of 30 days and each station is only effective in the range of 35 to $70 \mathrm{~km}$ depending on the tidal features of each sea area. This article presents the results of the model of the average and the lowest sea levels in the sea area of Vietnam, as a basis for referring the depth measurements of the seafloor to serve the construction of marine geographic information and making of charters to ensure maritime safety. $\mathrm{O}$ 